\title{
África y la Antropología española: la aportación del Instituto de Estudios Africanos ${ }^{1}$
}

\section{INTRODUCCIÓN}

La búsqueda de antecedentes históricos con vistas a afianzar una disciplina científica puede convertirse en un claro ejercicio de presentismo en el que todo se justifique con tal de conseguir la deseada dimensión histórica que consolide los discursos y las actuaciones que se quieran llevar a cabo: la actual antropología española no ha quedado exenta de esta tentación. Junto a esta actitud, también se ha dado en España la opuesta: una cierta negación u olvido sobre lo acontecido en la disciplina en un pasado más o menos reciente; ello, a la postre, ha generado notables lagunas y desconocimientos ${ }^{2}$.

En este sentido, llama poderosamente la atención el hecho de que cuando se repasan las biografías de algunos de los más reconocidos antropólogos españoles de nuestra centuria se encuentran trabajos realizados en África, en concreto, en las colonias españolas, circunstancia que no ha merecido la atención debida. Así, cabe preguntarse: ¿cómo y por qué Julio Caro Baroja realizó diversos estudios sobre el Magreb y sobre los saharauis? 3; ¿cómo y por qué Claudio Esteva Fabregat tuvo entre los fang de Río Muni su "más fuerte experiencia antropológica de contraste»? ${ }^{4}$

1 Una versión previa, más reducida y sin apéndice, ha sido publicada en la Revista de Antropología Aplicada, 1 (1996), pp. 155-159, con el título "En torno a algunos precedentes de la antropología aplicada en España".

2 De esta forma y tal como sugiere Fermín DEL PINO ("El nacionalismo en la etnologían, Ethnica, 12 [1976], p. 124), es significativo que, por ejemplo, Adam KUPER (Antropologia y antropólogos, Barcelona: Anagrama, 1973, p. 144) haya escrito (refiriéndose a la producción antropológica colonial) que: “[...] los españoles y los portugueses escasamente produjeron ningún tipo de antropologíam.

3 Ver Julio Caro Baroja, Una visión de Marruecos a mediados del siglo XVI (la del primer bistoriador de los "xarifes", Diego de Torres) (Madrid: Instituto de Estudios Africanos, 1956); Estudios mogrebies (Madrid: Instituto de Estudios Africanos, 1957) y Estudios sabarianos (Madrid: Instituto de Estudios Africanos, 1955).

4 Claudio Esteva Fabregat, “Autobiografía intelectual», Anthropos, 10 (1982), p. 12. 
¿cómo y por qué elaboró dos estudios claves sobre teoría y práctica de la antropología aplicada en los años setenta? ${ }^{5}$

Las respuestas a estas preguntas hay que buscarlas en el hecho de que antes de la institucionalización plena de la antropología española (último tercio de nuestro siglo ${ }^{6}$ ) hubo, entre los años cuarenta y setenta, un conjunto de aportaciones que, a pesar de no contar con un pleno reconocimiento académico e institucional, permiten vislumbrar cómo la antropología fue una disciplina que contó con un "espacio natural propio" de actuación y gozó de un cierto reconocimiento en los ambientes oficiales de la época ${ }^{7}$.

¿Cómo y por qué se avala la investigación antropológica en la España de las fechas señaladas?, ¿cúal fue ese "espacio natural»? Dejando de lado todo lo referido al mundo del folklore de ese momento, perfectamente estudiado por Carmen $\mathrm{Ortiz}^{8}$, la antropología española de aquella época tuvo un gran campo de acción en los territorios españoles de África: Norte de Marruecos (el antiguo Protectorado Español), Sahara español, Sidi Ifni (situado en la costa atlántica de Marruecos, frente a la isla de Lanzarote), Guinea Ecuatorial y las islas de Fernando Poo y Annobón en el Golfo de Guinea.

La actuación antropológica en estas posesiones debe inscribirse en la acción colonizadora española que desde el siglo XIX se venía desarrollando en África ${ }^{9}$ y que, con posterioridad a la Guerra Civil de 1936-1939, se

5 Ver "La antropología aplicada y su problemática", Alfredo JiMÉNEZ NúÑEZ (ed.)., Primera reunión de antropólogos españoles (Sevilla: Universidad de Sevilla, 1975), pp. 253-321; "Antropología aplicada: ¿comunidad o sistema?", VV.AA., Actas del I Congreso Español de Antropología (Barcelona: Universidad de Barcelona, 1980), I, pp. 231-282.

6 Es difícil fijar una fecha concreta, aunque existe un cierto consenso en la historiografía antropológica española en torno a la fecha de 1972, momento en el que se creó el primer Departamento de Antropología Cultural en la Universidad española, departamento que se constituyó en Barcelona bajo la dirección de Claudio Esteva Fabregat.

$7 \mathrm{Al}$ respecto, ver Luis Ángel SÁNCHEZ GOMEZ, "La antropología al servicio del Estado: el Instituto "Bernardino de Sahagún" del CSIC (1941-1970)", RDTP, XIVII (1992), pp. 29-44.

8 Ver su comunicación, "The political uses of Folklore by the Franco Regime", a la 4th Biennial Conference of the European Association of Social Anthropologists (Barcelona, julio de 1996).

9 Sobre la presencia española en territorio africano, ver Carlos SERRANO, "África y el problema de la colonización", Adolfo Domínguez (dir.), Historia de España (Barcelona: Planeta, 1991), vol. 11, pp. 143-186. En el momento de referirse a la colonización española de África, hay que tener en cuenta que, tal como señala el citado C. Serrano (p. 184), «el colonialismo español finisecular tiene evidentes implicaciones materiales y económicas; pero tiene no menores connotaciones míticas e ideológicas, 
fomentó de manera significativa con la creación y el apoyo a diversos organismos oficiales encargados de administrar esos territorios. Una de las tareas que llevaron a cabo dichos organismos fue estimular el conocimiento general sobre las posesiones citadas; buena parte de ese conocimiento tuvo, en gran medida, como uno de sus vectores fundamentales lo "aplicado", concepto que fue interpretado, básicamente, desde el punto de vista del aprovechamiento de los recursos naturales de las colonias. De esta forma, la actividad científica se centró en temáticas como la geografía, la geología, la topografía, la sanidad o la antropología (biológica y cultural), temáticas que, a la postre, podían ofrecer datos fehacientes para el establecimiento de unas u otras políticas. Como se puede observar, la idea de "aplicabilidad" era vista en aquellos momentos de forma muy diferente a como fue planteada por diversos antropólogos ${ }^{10}$ con posterioridad a la Segunda Guerra Mundial; de hecho, alentar investigaciones "aplicadas" fue una estrategia más que tenía por fin afianzar el establecimiento del sistema colonial y las argumentaciones sobre su necesidad y su bondad.

Los organismos oficiales que, en esencia, auspiciaron la investigación científica española en África fueron: el Instituto de Estudios Africanos [IDEA] del Consejo Superior de Investigaciones Científicas [CSIC], la Dirección General de Plazas y Provincias Africanas (también denominada Dirección General de Marruecos y Colonias), la Alta Comisaría de España en Marruecos y, en menor medida, el Instituto de Estudios Políticos. La creación de estas instituciones respondió a la orientación afro-imperialista ${ }^{11}$ que la política española adoptó a la finalización de la Guerra Civil, política que, por otra parte, intentó emular la actuación de otras potencias coloniales en África. De hecho, al repasar los presupuestos ideológicos y las formas de actuación utilizadas por España, al menos en lo concerniente al ámbito antropológico, no se aprecian ostensibles diferencias con la acción

que le dan sus dimensiones afectiva y pasionaln. Esta serie de atributos continuaron estando presentes en el período que se analiza en este artículo.

10 Al respecto, ver G. M Foster, Antropología aplicada (México: FCE, 1968), R. BASTIDE, Antropología aplicada (Buenos Aires: Amorrortu, 1972), L. MAIR, "Applied Anthropology", International Encyclopedia of the Social Sciences (New York: Crowell Collier and Macmillan, Inc., 1968), vol. I, pp. 325-330.

11 Ver Manuel TuÑón DE LARA y José BIESCAS, Historia de España (Barcelona: Ed. Labor, 1982), vol. X, pp. 291-293. Por otra parte, dicha orientación se vio complementada con un cierto irrendentismo africanista español que reclamaba y justificaba su protagonismo y su presencia en África. Una buena muestra fue la conferencia que impartió Tomás García Figueras el día 4 de octubre de 1942 en el Teatro Principal de Barcelona titulada Reivindicaciones de España en el Norte de África (editada en Madrid en 1944 bajo el mismo título). 
que otras potencias occidentales ya venían desarrollando desde hacía años en el continente africano.

Este artículo, breve en su extensión aunque el tema es muy amplio, presenta la investigación antropológica que auspició el IDEA, investigación que, desde mi punto de vista, ofrece diversos elementos que ayudan a comprender mejor la historia de la antropología española del siglo $\mathrm{xx}$, aportando datos que permiten evaluar, de manera más precisa, ciertas actuaciones así como observar el universo ideacional y formal de la antropología practicada, o las arritmias y los desfases que se generaron con respecto a la producción y a las orientaciones antropológicas internacionales del momento. Así, mientras el IDEA patrocinaba investigaciones tendentes al conocimiento de los territorios coloniales bajo el prisma de la reivindicación histórica de un legado patrio determinado, la dinámica antropológica internacional, posterior a la Segunda Guerra Mundial, ya había iniciado una revisión crítica del papel que había jugado, por ejemplo, la jurisprudencia occidental en el establecimiento del orden colonial o su interés se centraba en la llamada "antropología del orden" (análisis del proceso de disputa, etc.) ${ }^{12}$.

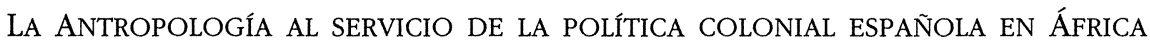

El IDEA fue la institución que fomentó, de manera más clara, la investigación científica en las posesiones españolas africanas. Se fundó a mediados de 1946 en el seno del Patronato "Diego Saavedra Fajardo" de Estudios Internacionales del CSIC y sus principales funciones eran: "la labor investigadora y la labor difusora común a todos los Institutos del CSIC" ${ }^{13}$.

12 Ver Simon RoBerTs, "Law and Dispute Process", Tim INGOLD (ed.), Companion Encyclopedia of Antbropology (Londres: Routledge, 1994), pp 962-982.

13 Memoria del Consejo Superior de Investigaciones Científicas. 1948 (Madrid: CSIC, 1950), p. 298. Hay que recordar que, tal como han señalado algunos historiadores de la ciencia (ver José Manuel SÁNCHEZ RON, "Política científica e ideología: Albareda y los primeros años del Consejo Superior de Investigaciones Científicas", Boletín de la Institución Libre de Enseñanza, 14 [1992], pp. 53-74; M. José SANTESMASES y Emilio MUÑOZ, "Las primeras décadas del CSIC. Una introducción a la política científica del régimen franquistan, Boletín de la Institución Libre de Enseñanza, 16 [1993], pp. 73-94), durante las primeras décadas de la postguerra, el CSIC, y por tanto el IDEA, además de ser organismos de investigación, jugaron un destacado papel en el establecimiento de relaciones internacionales por parte de España; es el caso, por ejemplo, de la IV Conferencia Internacional de Africanistas Occidentales celebrada en Santa Isabel de Fernando Poo (5-12 de diciembre de 1951). Además, ver Memoria del Consejo Superior de Investigaciones Científicas. 1948 (Madrid: CSIC, 1950), p. 299. 
Desde sus inicios, el IDEA estuvo estrechamente vinculado a los otros organismos oficiales mencionados, lo que hizo que buen número de acciones se realizasen en colaboración con ellos, como es el caso del patrocinio del Museo de África, institución que antes y después de su inauguración tuvo una existencia ciertamente problemática.

El general José Díaz de Villegas y Bustamante, buen conocedor de los territorios africanos, fue nombrado director del IDEA; y con posterioridad también de la Dirección General de Marruecos y Colonias. Su vinculación a tareas científicas o de promoción de la ciencia no era excepcional; otros militares también participaron, algunos de manera muy activa, en el IDEA, siguiendo, posiblemente, el ejemplo de otros países coloniales, como Francia. De hecho, que diversos miembros del ejército trabajasen activamente en el Instituto es un dato que hay que tener en cuenta para futuros estudios. Algunos de ellos, sensibles a las culturas locales, adquirieron importantes conocimientos sobre las formas de vida de las poblaciones autóctonas, realizando aportaciones interesantes a su conocimiento etnográfico ${ }^{14}$.

La investigación antropológica que auspició el IDEA debe inscribirse en el marco de la actuación colonial de las potencias europeas ${ }^{15}$ que, todavía a mediados de los años cuarenta y cincuenta, continuaban controlando buena parte de África, aunque, en el caso de nuestro país, hay que tener en cuenta la perpetuación del discurso finisecular sobre África (ver infra nota 9): ésta siguió teniendo un peso notable en las argumentaciones de las décadas posteriores a 1940. En este sentido, España, al igual que otros estados colonizadores, estaba destinada a desarrollar un papel civilizador, de orden, de progreso (la conocida "misión civilizadora"). Estos planteamientos conllevaron que la antropología tuviese como una de sus funciones básicas orientar políticas tendentes a conseguir tales objetivos, como así se puede leer en el siguiente texto:

14 Por ejemplo, ver los artículos sobre el folklore baamarani que el Teniente Coronel Doménech Lafuente publicó en la revista África (números IV, VII y VIII, 1944).

15 Sobre la relación entre el desarrollo de la antropología y el colonialismo, hay una abundante literatura; en este sentido, ver, entre otras obras, Gérard LECLERC, Anthropologie et colonialisme. Essais sur l'bistoire de l'africanisme (Paris: Fayard, 1972. Traducción castellana: Madrid: Alberto Corazón, 1973), Talal ASAD (ed.), Anthropology and The Colonial Encounter (Londres: Ithaca Press, 1973); Adam Kuper, Antropología y antropólogos. La Escuela Británica 1922-1972 (Barcelona: Anagrama, 1973), J. R. LloBERA (ed.) La Antropología como ciencia (Barcelona: Anagrama, 1975) y Jack GoODY, The Expansive Moment. Anthropology in Britain and Africa 1918-1970 (New York: Cambridge University Press, 1995). 
[los Cuestionarios proporcionarán] un conocimiento total de las características del pueblo marroquí fijadas a través de los siglos, conocimiento que nos llevará a una mayor comprensión del pueblo marroquí, base no solamente de un amor bien fundamentado, sino también de una mayor garantia de acierto en la labor que corresponde a España de bacer evolucionar la vida marroqui baciéndole alcanzar un mayor grado de progreso $y$ de bienestar ${ }^{16}$.

Este tipo de actitudes suponían un cierto paternalismo hacia las poblaciones autóctonas ${ }^{17}$ que eran presentadas, en muchos casos, con escasas dotes y habilidades ${ }^{18} \mathrm{y}$, por lo tanto, necesitadas de tutelas foráneas.

En segundo término, hay que tener en cuenta las corrientes de pensamiento antropológico dominantes por aquel entonces en España. Aparte de ciertas excepciones, caso de Caro Baroja con el funcionalismo, se puede decir que, en términos generales, la escuela histórico-cultural de Graebner y del P. Schmidt, con sus planteamientos difusionistas y su preocupación por el origen de los elementos culturales ${ }^{19}$, tenía una fuerte presencia en las argumentaciones e investigaciones de aquel tiempo. Dicha corriente se veía acompañada por una importante preocupación por la descripción y el análisis antropométrico de los individuos, que se convirtió, en muchos casos, en una plataforma ideal para realizar extrapolaciones de carácter socio-cultural ${ }^{20}$. Éstas, por otra parte, presentaban todavía fuertes

16 AlTA COMISARÍA DE ESPAÑA EN MARRUECOS, Investigación científica de Marruecos. I. Cuestionarios de Etnologia, Lingüistica y Arqueología (Larache, 1940), p. 6. Subrayado mío.

17 Así, por ejemplo: "Son muy supersticiosos: colocan amuletos al cuello de los niños para evitarles el mal de ojo. Creen en la existencia de demonios y de espíritus maléficos. Esperan la muerte con serenidad y resignación y no lloran a los muertos". Tomás García Figueras y J. L. Fernández-Llebrez. Manuales del África española. II. Marruecos (Madrid: IDEA, 1955), p. 77.

18 El siguiente texto es ilustrativo al respecto: "El pamue, como agricultor, es una verdadera desdicha, pues la creación y cultivo de una finca es el destrozo y aniquilamiento de una parte más o menos grande del bosque [...] como el indígena desbosca mal, cultiva mal, y además las plantas que cultiva suelen ser esquilmantes - caso típico de la yuca-, al cabo de unos años la parcela aquella ha quedado totalmente improductiva; entonces el pamue piensa en formar una nueva finca, y la devastación del bosque prosigue ininterrumpidamente", Juan BONELLY Y RUBIO. "Notas sobre la geografía humana de los territorios españoles del Golfo de Guinean, José DíAZ DE VIllegas et. al., España en África (Madrid: IDEA, 1949), p. 186.

19 Así, a la hora de comentar los resultados de los estudios antropométricos realizados durante la Expedición Científica a Guinea en 1948, se dijo: "La Sección Antropológica promete brindar interesantes enseñanzas que han de aclarar tanta incógnita como envuelve la existencia del mundo negro del África Ecuatorial", Memoria del Consejo Superior de Investigaciones Cientificas. 1948 (Madrid: CSIC, 1950), p. 299.

20 La relación entre caracteres raciales y culturales, derivación de las fuertes concepciones socio-biologistas de la década de los años treinta en Europa, se apreció en 
influencias de lo que podría denominarse como una cierta "psicología costumbrista", heredera de la psicología de los pueblos ${ }^{21}$, ya extinguida en medios científicos internacionales. En este sentido, uno de los planteamientos más destacados sobre la utilidad analítica de la relación entre biología y cultura fue el denominado mosaico raciológico, expuesto por Santiago Alcobé Noguer, catedrático de antropología física de la Universidad de Barcelona, que permitía: “[...] acceder a un mejor conocimiento de los distintos pueblos que habían participado en la configuración de una determinada cultura" ${ }^{22}$, idea, por otra parte, no exenta de posibles connotaciones racistas ${ }^{23}$, más cuando la vinculación entre naturaleza y cultura, entre medio ambiente y aptitud intelectual y psicológica ${ }^{24}$ de los individuos, estaba muy presente ${ }^{25}$. De hecho, esta creencia venía a confirmar,

numerosos textos y trabajos de los años cuarenta auspiciados por el IDEA: "[...] otro aspecto de nuestras investigaciones, el psicológico-racial, efectuado especialmente a base del psicodiagnósticos de Rorschach y bajo la orientación de las ideas de Clauss y de Ortner sobre "estilos raciales" y tipos biológicos [...]". Antonio LINARES MAZA, "Estudios para una antropología del territorio de Ifni", Trabajos del Instituto Bernardino de Sabagún de Antropología y Etnología, III (1946), p. 11.

21 Ver Jesús FERNÁNDEZ CABEZAS, La personalidad pamúe desde el punto de vista biotipológico (Madrid: IDEA, 1951). Una muestra de este tipo de argumentaciones: "el carácter marroquí es, en síntesis, orgulloso [...] valiente, amante del dinero, generoso en la hospitalidad, tímido y pudoroso [...] fatalista, es, sin embargo, supersticioso, y amuletos, sortilegios y conjuros son prácticas acostumbradísimas entre ellos", Antonio OCHOA IGLESIAS, "Síntesis de geografía humana y económica de Marruecos", José DíAz DE VIllegAs, et. al., España en África (Madrid: IDEA, 1949), p. 69.

22 Luis Calvo Calvo, "Alcobé Noguer, Santiago", Carmen OrTIZ y Luis Ángel SáNCHEZ (eds.), Diccionario bistórico de la Antropología española (Madrid: CSIC, 1994), p. 55 .

23 La rotundidad de la afirmación no está exenta de ciertas dudas ya que la teoría de los equilibrios puntuales planteada por Eldredge y Gould en 1972 demuestra que las clasificaciones tipológicas, y sus consecuencias más inmediatas, utilizadas en la primera mitad del siglo xx no eran tan anacrónicas. Al respecto, ver Antoni PREVOSTI, "La Genètica a la Universitat de Barcelona", VV. AA., Història de la Universitat de Barcelona (Barcelona: Universitat de Barcelona, 1990), p. 529.

24 Hay que señalar que para confirmar la capacidad intelectual y psicológica de los indígenas, se realizaron numerosos tests psicológicos entre éstos. Al respecto, ver Ricardo IBARROLA, "Aportación al estudio del nivel mental de los indígenas de Guinea", Archivos del IDEA, núm. 18. Además, recuérdese que en una de las expediciones del IDEA y del CSIC, se creó ex-profeso una comisión de Psicotecnia. Ver infra notas 28 y 30 .

25 De esta forma, se llegó a decir que: «Los individuos, las razas, sobre todo, cuanto menos civilizadas son, su manera de vivir, sus costumbres, sus caracteres, están íntimamente unidos al medio ambiente en el cual se desarrollan [...]p, Juan de LIZAUR Y ROLDÁN, "Geología y geografía física de la Guinea continental española", José DíAZ DE 
una vez más, la naturaleza biológica de la cultura y el estadio de subdesarrollo de las poblaciones colonizadas. La antropología se convertía así en un poderoso aliado de la colonización.

El IDEA, recogiendo el testigo de otros organismos que venían trabajando desde hacía tiempo en las posesiones españolas ${ }^{26}$, auspició numerosas investigaciones. Por lo que respecta a la antropología, dicho Instituto tuvo una gran sensibilidad, hasta el punto de que uno de sus proyectos más importantes fue la creación de Museo de África ${ }^{27}$, básicamente de carácter antropológico. La precaria situación institucional de la disciplina por aquellos años en España impidió que hubiese un desarrollo más elevado y, al fin, una reflexión crítica sobre el propio trabajo antropológico en las colonias.

La investigación antropológica que se llevó a cabo osciló entre la analítica de lo biológico (en especial, antropometría, grupos sanguíneos, etc.) y el estudio de los rasgos culturales de las poblaciones indígenas. El IDEA consiguió reunir una nutrida información sobre la sociedad y la cultura de las posesiones españolas africanas, ya fuese a través de la financiación de trabajos de campo, del aprovechamiento de los conocimientos de militares y de misioneros conocedores de las culturas locales, o bien patrocinando expediciones científicas como la realizada a Guinea durante el ve-

VILlEGAS, et. al., España en África (Madrid: IDEA, 1949), p. 151. Un segundo testimonio confirma la creencia generalizada en la íntima asociación entre medio ambiente y cultura: "Al hombre no puede concebírsele como colectividad desligado de su país. El terruño imprime un sello indeleble a sus hijos, y más cuanto más primitivos son éstos, pues su vida es más "natural", está más cerca de la Naturaleza". Antonio LiNARES MAZA, "Estudios para una antropología del territorio de Ifni", Trabajos del Instituto Bernardino de Sabagún de Antropología y Etnología, III (1946), p. 11.

26 Así, por ejemplo, antes de la creación del IDEA, los organismos oficiales arriba mencionados auspiciaron diversas expediciones científicas, algunas de carácter antropológico (entendido, básicamente, como historia primitiva y antropología física). Ver E. y F. HERNÁNDEZ PACHECO, "Sabara español. Expedición científica de 1941 (Madrid: Universidad de Madrid. Servicio de Publicaciones, 1942); B. SÁEZ MARTín, “La primera expedición paletnológica al Sahara español", África, 27 (1944), pp. 14-17; A. MARcos Pons, "Expedición Etnológica y Paletnológica a la Guinea española", Cuadernos de Historia Primitiva, 2 (1946), p. 110; J. MARTínez SANTAOlalla, El Sahara español anteislámico. (Algunos resultados de la primera expedición paletnológica al Sabara, julio-septiembre de 1943) (Madrid: 1944); S. ALCOBÉ NOGUER, "Grupos sanguíneos en nómadas del Sahara occidental", Trabajos del Instituto Bernardino de Sabagún, 1 (1945), pp. 23-37 y "The phisical anthropology of the west saharian nomads", Man, XIVII, 160 (1947), pp. 141143; M. Almagro Basch, Prebistoria del Norte de África y del Sahara español (Madrid: IDEA, 1946).

27 Carmen Ortiz García, "Els museus d'ultramar i colonials a Espanya", Revista d'Etnologia de Catalunya, 7 (1995), p. 24. 
rano de 1948 y dirigida por el citado Alcobé Noguer ${ }^{28}$, expedición que estuvo formada por diversas comisiones: Antropología (física), Etnología, Entomología y Geología. En esta expedición, en lo que hace referencia a la antropología, Alcobé realizó estudios antropométricos y sanguíneos sobre 1398 individuos de las etnias pamues (fang), combes y bubis. Panyella Gómez, secretario de la expedición y ayudante de Alcobé, fue el responsable de los estudios etnológicos que se centraron, sobre todo, en la recolección de cultura material para el futuro Museo de África así como en la adquisición de instrumentos musicales indígenas para el Museo de la Música de Barcelona. Además, también se obtuvieron datos sobre tatuajes fang, el sistema de parentesco y el régimen económico de esta población ${ }^{29}$. Dejando de lado los logros científicos, una de las consecuencias ${ }^{30}$ más importantes de este viaje fue la fundación del Museo Etnológico y Colonial de Barcelona en 1949, hoy Museu Etnològic de Barcelona, gracias al entusiasmo de Panyella, el apoyo de Alcobé y las antiguas aspiraciones museísticas del entonces ponente de cultura del Ayuntamiento de Barcelona, Tomàs Carreras i Artau, fundador del Archivo de Etnografía y Folklore de Cataluña.

Además del legítimo espíritu científico y cultural, fruto del cual fueron algunos trabajos notables, como los mencionados de Caro Baroja ${ }^{31}$, buen número de los estudios que el IDEA auspició y publicó tuvieron como finalidad básica ser un instrumento más para consolidar la colonización y establecer planes de desarrollo que permitiesen un mayor y mejor aprovechamiento de los recursos humanos y naturales de las colonias ${ }^{32}$, aunque este aspecto no llegó a ser efectivo, a pesar de algunas tentativas; en este sentido, las palabras de Esteva Fabregat, referidas a su estancia en Guinea en los años 1962-1963, son ilustrativas:

28 Ver Santiago AlCOBÉ Noguer, "Una expedición científica a los territorios españoles del Golfo de Guinean, Archivos del IDEA, 10 (1949); August Panyella Gómez. "Expedición científica a los territorios españoles del Golfo de Guinea", Ampurias, XI (1949), pp. 208-109.

29 August PANYella GómeZ, "Expediciones españolas a África”, Zephirus, 2 (1951), pp. 111-114.

30 También hay que mencionar que, dado el éxito de esta expedición, el CSIC, en 1949, organizó otro viaje científico a Guinea, que tuvo como áreas de interés la Zoología, la Geología y la Psicotecnia.

31 Ver supra nota 3.

32 Ver Jaime Nosti NAVA, Agricultura de Guinea promesa para España (Madrid: IDEA, 1946). 
[...] el objeto de mis estudios en Guinea consistía en proporcionar materiales etnográficos y ofrecer observaciones y consejos relativos a la receptividad indígena de un Plan de Desarrollo Económico en aquella región [...] auspiciado por la Comisión del Plan de Desarrollo Económico de la Guinea Española, que dirigía el doctor Juan Velarde Fuertes [...] ${ }^{33}$.

Un análisis ${ }^{34}$ de las publicaciones ${ }^{35}$ del IDEA entre 1947 y 1964 confirma, de una parte, el apoyo que recibió la antropología en los medios oficiales de la época y, de otra, el sentido aplicado de buena parte de las investigaciones que se auspiciaron desde aquél. Los gráficos y tablas que se adjuntan en el Apéndice muestran cómo la antropología (física y cultural) fue una de las disciplinas científicas más cultivadas frente a otras que, en principio, podían tener más importancia. Los gráficos que registran la distribución geográfica de dichas publicaciones muestran cómo las posesiones en el Golfo de Guinea fueron las colonias más ricas y rentables ${ }^{36}$.

¿Cuáles fueron las características de las publicaciones de tema antropológico del IDEA? Un somero análisis permite observar que, en primer lugar, las investigaciones antropobiológicas se llevaron a cabo, en la mayoría de los casos, con un espíritu morfologista, preocupándose, básicamente, por la descripción antropométrica de los individuos. Estos trabajos tenían como fin básico obtener datos para implementar políticas sanitarias y, como ya he apuntado, evaluar las capacidades y actitudes de los grupos indígenas con vistas a su utilización económica. En segundo término, los estudios de carácter cultural y social tuvieron como uno de sus fines primordiales todo lo referido a la tradición oral, dándose pocos casos donde se intentara profundizar en las estructuras sociales de los pueblos autóctonos. Los mencionados trabajos de Caro Baroja sobre los saharauis, los de Panyella

33 Claudio Esteva Fabregat, "Autobiografía intelectual", Antbropos, 10 (1982), p. 12.

34 Ver Apéndice.

35 Ver Publicaciones del Consejo Superior de Investigaciones Científicas 1940-1964 (Madrid: CSIC, 1964), pp. 427-452. Hay que hacer constar que el IDEA tuvo dos publicaciones periódicas: África, de tono básicamente divulgativo, y los Archivos del IDEA, cuyo carácter fue mucho más riguroso y científico; ambas revistas publicaron numerosos artículos sobre los temas aquí estudiados. También es interesante consultar los Trabajos del Instituto Bernardino de Sabagún donde se publicaron diversos estudios antropológicos de tema africano.

36 Al respecto, ver María Encarna Nicolás MARín, "El franquismo", Antonio DomínGUEZ ORTIZ (dir.), Historia de España (Barcelona: Planeta, 1991), vol. 12, pp. 117-119.

37 Ver August PANYElla GÓMEZ y Jorge SABATER PI, "Los cuatro grados de la familia en los Fang de la Guinea española, Camarones y Gabón", Archivos del IDEA, 40 (1957), pp. 7-32.

38 Ver Claudio ESTEVA FABREgat, "Algunos caracteres del sistema de propiedad "fang", Ethnica, 1 (1971), pp. 31-59. 
y Sabater Pi sobre los fang ${ }^{37}$ y los más tardíos de Esteva sobre esta misma etnia, son las excepciones ${ }^{38}$.

Del conjunto de trabajos antropológicos acogidos por el IDEA, de mayor o menor envergadura o fortuna, creo que hay que resaltar un aspecto: todos ellos supusieron uno de los estímulos más importantes para la configuración de las primeras teorizaciones y argumentaciones explícitas en favor de una antropología aplicada en España, en concreto, las realizadas por Esteva en dos ponencias en sendas reuniones antropológicas de los años setenta ${ }^{39}$, ponencias que tuvieron como eje central destacar el peso específico que la antropología tiene en los procesos de cambio cultural, donde los antropólogos pueden jugar un papel relevante en la planificación de las nuevas realidades socio-culturales de etnias que se vean afectadas por transformaciones en sus estructuras económicas, sociales y culturales, papel que, al menos, cuestiona las argumentaciones, las actitudes y las actuaciones clásicas de la disciplina ${ }^{40}$.

A modo de conclusión y entre los diferentes aspectos que cabría mencionar, opto por insistir en la necesidad de aquilatar las afirmaciones y los planteamientos sobre nuestra historia disciplinar; en este sentido, cada vez es más necesario evaluar, en su justa medida, algunas de las que se presentan como novedosísimas argumentaciones y propuestas.

\author{
Luis Calvo Calvo \\ Institución Milá y Fontanals \\ CSIC. Barcelona
}

El estudio quiere mostrar la actuación, de carácter antropológico, que el Instituto de Estudios Africanos (IDEA) desarrolló a lo largo de más de tres décadas, aproximadamente entre 1940 y 1970 . A pesar de la precariedad institucional de la disciplina, el IDEA auspició una serie de investigaciones que permiten vislumbrar cómo la Antropología fue utilizada como un instrumento más para llevar a cabo determinadas políticas entre los pueblos africanos bajo soberanía española.

The author discusses the research in anthropology that Spain's Institute of African Studies (IDEA) promoted over more than three decades, approximately from 1940 through 1970. Although its resources were limited, the Institute sponsored in those years a number of research projects that reveal the extent to which antrhopology was used as an instrument of government policy towards the indigenous peoples of Africa under Spanish rule.

39 Ver supra nota 5.

40 Luis Calvo Calvo, Claudio Esteva Fabregat y la Antropología Aplicada (Universidad de Barcelona: tesis de licenciatura, inédita, 1985), pp. 72-74. 


\section{APÉNDICE}

GRÁFICO 1

LIBROS DEL IDEA (1947-1964) ${ }^{41}$ : DISTRIBUCIÓN GEOGRÁFICA

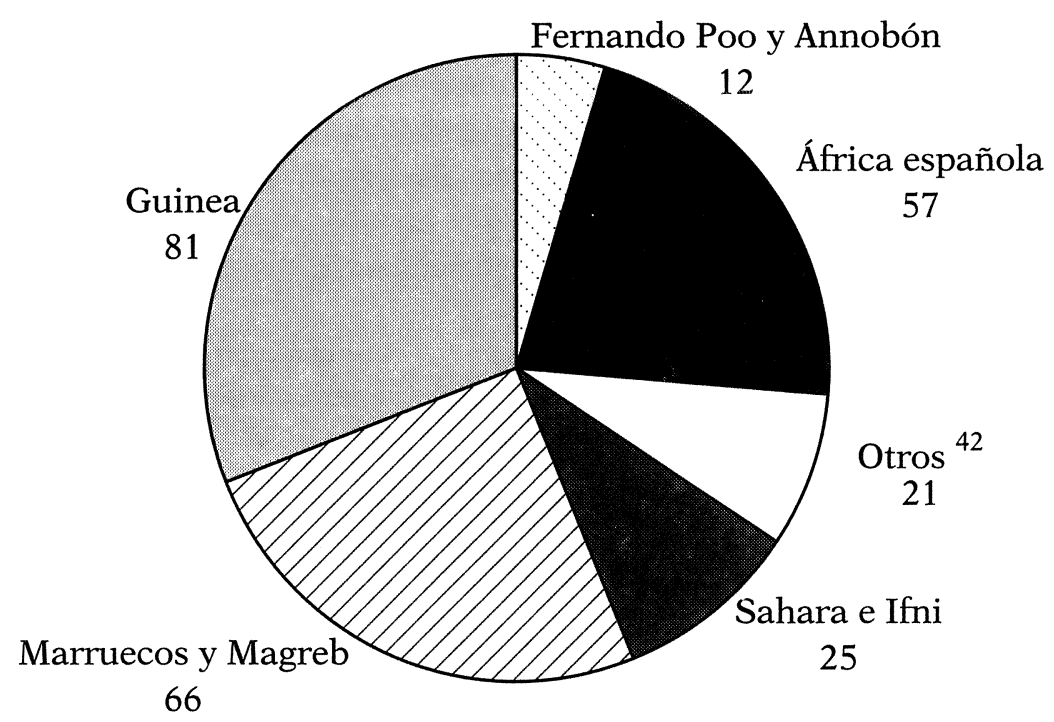

41 Fuente: Publicaciones del Consejo Superior de Investigaciones Científicas 1940-1964 (Madrid: CSIC, 1964), pp. 427-452.

42 Incluye: África atlántica (2), Angola (1), Congo (2), Gibraltar (9), Mediterráneo (5) y Muni (2). 
GRÁFICO 2

LIBROS DEL IDEA (1947-1964) ${ }^{43}$ : MATERIAS

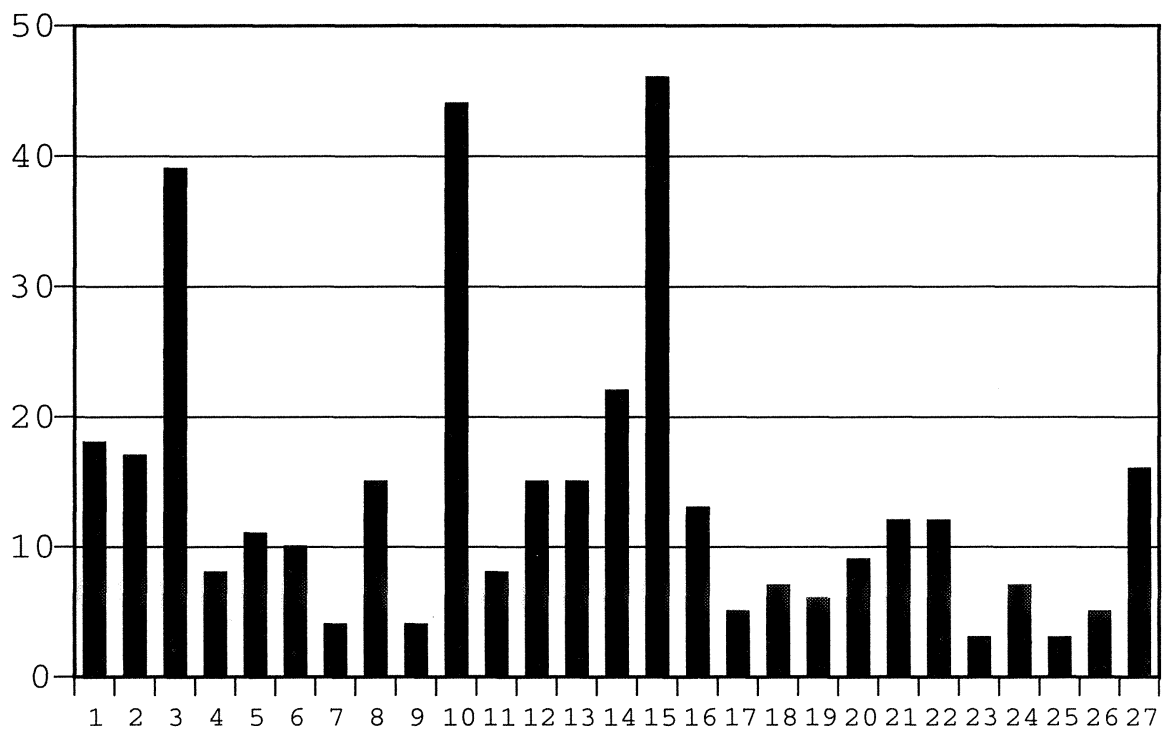

1. Administración colonial: 18

2. Agricultura (técnicas, recursos forestales, caza, pesca): 17

3. Antropología biológica y Etnología: 39

4. Bibliografía: 8

5. Biología (Botánica y Zoología): 11

6. Comunicaciones: 10

7. Conferencias y congresos: 4

8. Derecho: 15

9. Economía: 4

10. Ensayo y divulgación (Día de África, visitas oficiales): 44

11. Enseñanza: 8

12. Estadística: 15

13. Geología: 15

14. Geografía (física, humana, cartografía, meteorología): 22

15. Historia (biografía, historia de la ciencia): 46

16. Lingüística (diccionarios, dialectos, toponimia): 13

17. Literatura: 5

18. Medicina y Farmacia: 7

19. Mediterráneo: 6

20. Milicia: 9

21. Mundo árabe (diferentes aspectos): 12

22. Música y pintura: 12

23. Población: 3

24. Política: 7

25. Prehistoria y Arqueología: 3

26. Religión: 5

27. Varia: 16

43 Fuente: ver supra nota 41 


\section{GRÁFICO 3}

ARCHIVOS DEL IDEA (1947-1964). ARTíCULOS: DISTRIBUCIÓN GEOGRÁFICA

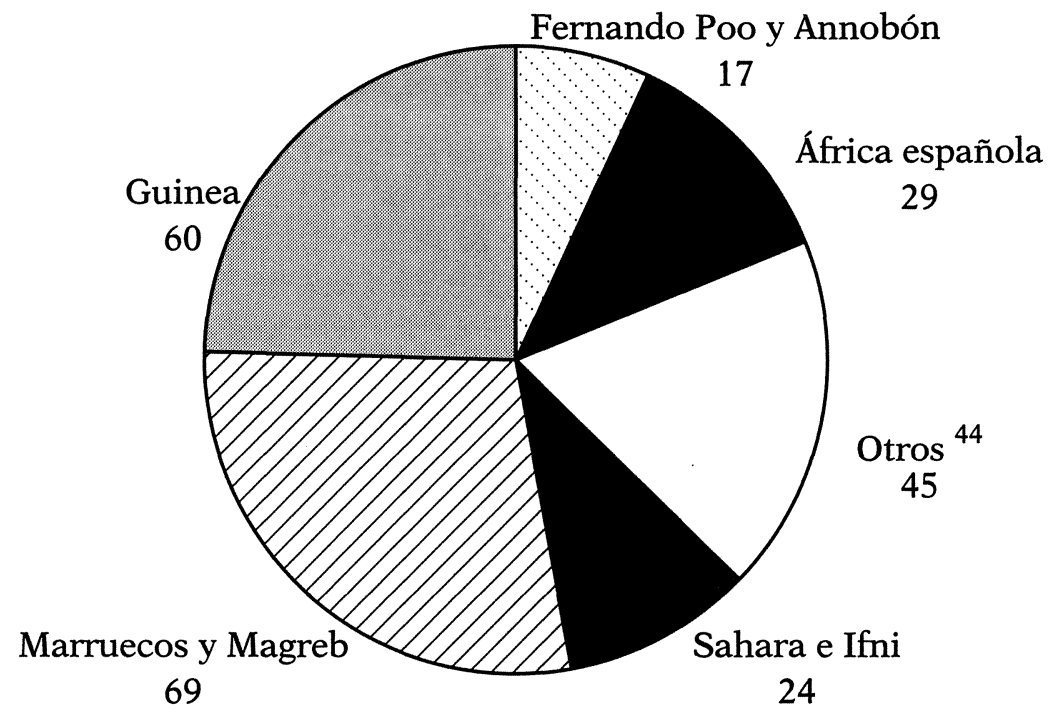

44 Incluye: Abisinia, África atlántica, Angola, Argel, Congo, Gibraltar, Mediterráneo, Muni, Rusia. 
GRÁFICO 4

ARCHIVOS DEL IDEA (1947-1964). ARTícULOS: MATERIAS

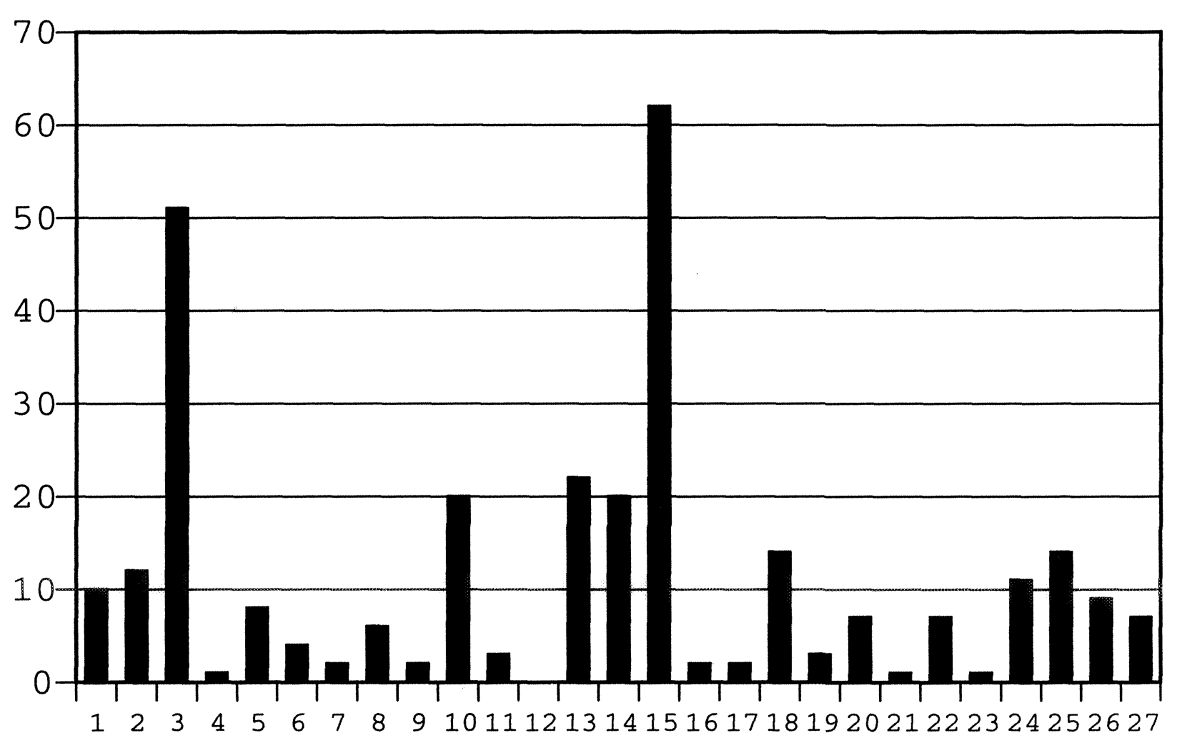

1. Administración colonial: 10

2. Agricultura (técnicas, recursos forestales, caza, pesca): 12

3. Antropología biológica y Etnología: 51

4. Bibliografía: 1

5. Biología (Botánica y Zoología): 8

6. Comunicaciones: 4

7. Conferencias y congresos: 2

8. Derecho: 6

9. Economía: 2

10. Ensayo y divulgación (Día de África, visitas oficiales): 20

11. Enseñanza: 3

12. Estadística: 0

13. Geología: 22

14. Geografía (física, humana, cartografía, meteorología): 20

15. Historia (biografía, historia de la ciencia): 62

16. Lingüística (diccionarios, dialectos, toponimia): 2

17. Literatura: 2

18. Medicina y Farmacia: 14

19. Mediterráneo: 3

20. Milicia: 7

21. Mundo árabe: 1

22. Música y pintura: 7

23. Población: 1

24. Política: 11

25. Prehistoria y Arqueología: 14

26. Religión: 9

27. Varia: 7 


\section{GRÁFICO 5}

PUBLICACIONES DEL IDEA. TOTALES (GRÁFICOS $1+3$ ): DISTRIBUCIÓN GEOGRÁfICA

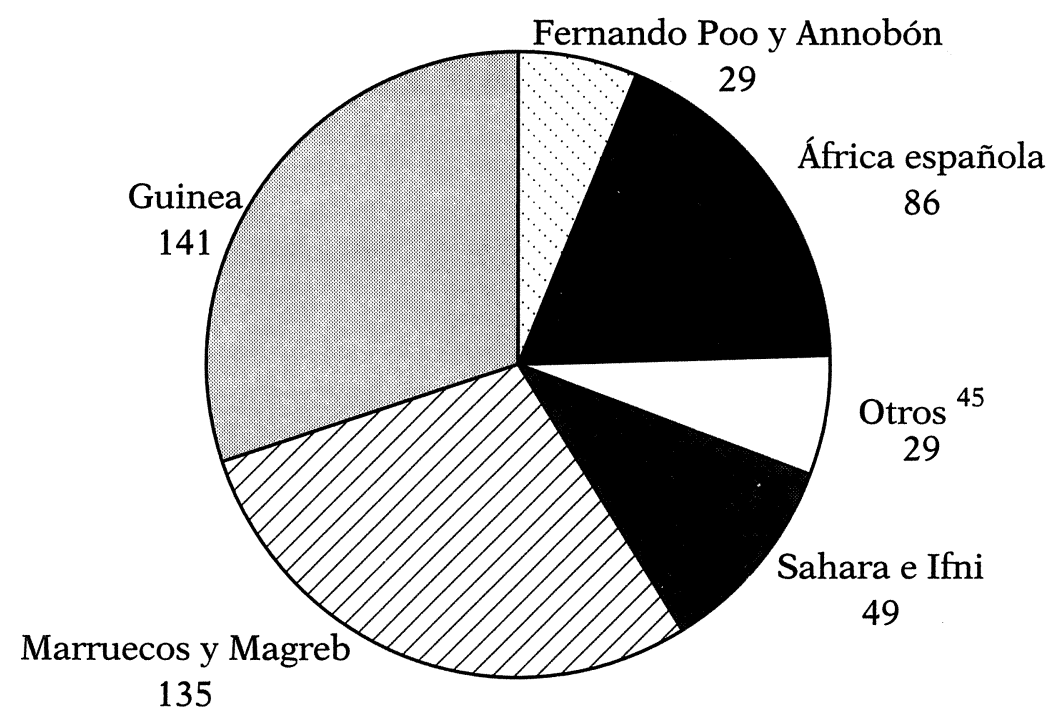

${ }^{45}$ Ibid. 
GRÁFICO 6

PublicACiones Del IDEA. TOtAles (GRÁFICOS $2+4$ ): MATERIAS

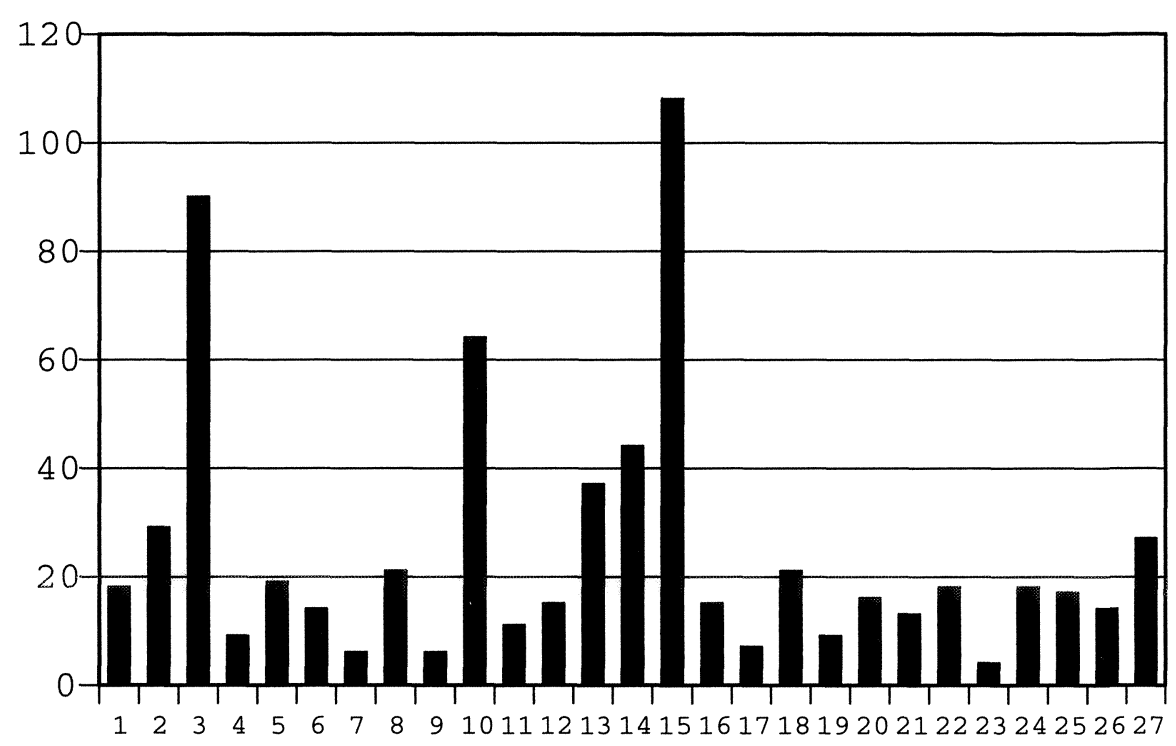

1. Administración colonial: 18

2. Agricultura (técnicas, recursos forestales, caza, pesca): 29

3. Antropología biológica y Etnología: 90

4. Bibliografía: 9

5. Biología (Botánica y Zoología): 19

6. Comunicaciones: 14

7. Conferencias y congresos: 6

8. Derecho: 21

9. Economía: 6

10. Ensayo y divulgación (Día de África, visitas oficiales): 64

11. Enseñanza: 11

12. Estadística: 15

13. Geología: 37

14. Geografía (física, humana, cartografía, meteorología): 44

15. Historia (biografía, historia de la ciencia): 108

16. Lingüística (diccionarios, dialectos, toponimia): 15

17. Literatura: 7

18. Medicina y Farmacia: 21

19. Mediterráneo: 9

20. Milicia: 16

21. Mundo árabe: 13

22. Música y pintura: 18

23. Población: 4

24. Política: 18

25. Prehistoria y Arqueología: 17

26. Religión: 14

27. Varia: 27 